\title{
Dynamic active power control in Mosul city ring system using ESTATCOM
}

\author{
Dhiya A. Al-Nimma, Majid S. M. Al-Hafidh, Saad Enad Mohamed \\ Electrical Engineering Department, University of Mosul, Mosul- IRAQ \\ Email address: \\ dalnimma@ieee.org(Dhiya A.Al-Nimma),el_noor2000@yahoo.co(Majid S. M.Al-Hafidh), \\ saadenadmohamed@yahoo.com(S. E. Mohamed)
}

\section{To cite this article:}

Dhiya A. Al-Nimma, Majid S. M. Al-Hafidh, Saad Enad Mohamed. Dynamic Active Power Control in Mosul City Ring System Using ESTATCOM. American Journal of Electrical Power and Energy Systems. Vol. 2, No. 5, 2013, pp. 116-122. doi: 10.11648/j.epes.20130205.12

\begin{abstract}
Static synchronous compensation (STATCOM) is an application that utilizes a voltage source converter (VSC) to provide instantaneous reactive power support to the connected power system. Conventionally, STATCOMs are employed for reactive power support only. However, with the integration of energy storage (ES) into a STATCOM, it can provide active power support in addition to the reactive power support. The control method of a STATCOM with an energy storage device is discussed in this paper. To determine the switching level control, SPWM (Sinusoidal Pulse Width Modulation) methods is used. This paper will introduce an integrated STATCOM/BESS for the improvement of dynamic and transient stability and transmission capability. This work suggests a simple and easy to implement PI controller to control the operation of ESTATCOM placed at the weak point of Mosul city $132 \mathrm{kV}$ ring system. The whole system including the ESTATCOM and its controller has been simulated after some kinds of disturbances and the results show improvements in the dynamic active and reactive power capabilities of the system.
\end{abstract}

Keywords: ESTATCOM, Active Power Control, Dynamic Active and Reactive Power Capabilities, Battery Energy Storage

\section{Introduction}

The Iraqi national grid is divided into sub grids on geographical bases. The Iraqi Northern Region National Grid (INRNG) is one of these sub grids. Mosul city is part of this (INRNG) and it is supplied by one $400 \mathrm{kV}$ substation at Bus 6 and seven $132 \mathrm{kV}$ substations. These substations form a ring consists of seven $132 \mathrm{kV}$ buses. The lines connecting the buses are mainly of two circuits. There are three single circuit lines. This part of INRNG suffers from problems such as loading on these three lines can exceed the accepted loading percent during peak load periods. This causes outage due to over load.

STATCOM as reactive power compensation has been used in a pervious study to improve the voltage profile in Mosul Ring System, which can also be used to determine the optimal value of the reactive power needed at different load conditions [1].

Later study used STATCOM with Energy storage device as active power compensation [2].

In this work a PI controllers has been suggested and added to the same system to control its operation during some kinds of disturbances. The transient behavior of the whole system has been studied via modeling and simulation. The results so obtained were compared with those obtained without the controller and the results are discussed.

\section{Modeling of Mosul City Ring System}

The largest part of Iraqi Northern Region National Grid (INRNG) is Mosul ring and this part of the grid is modeled by using MATLAB SIMULINK program. The MUSOL ring includes two generator units one of them is hydraulic and the other is Gas Station and the Grid connected with power lines and this grid is shown in figure (1). In previous study we found that the weak point in MOSUL grid is located at BUS 37 and depending on this study we suggested to put the STATCOM with energy storage system at that location [3]. The SIMULINK model of the grid with STATCOM is shown in appendix (2). 


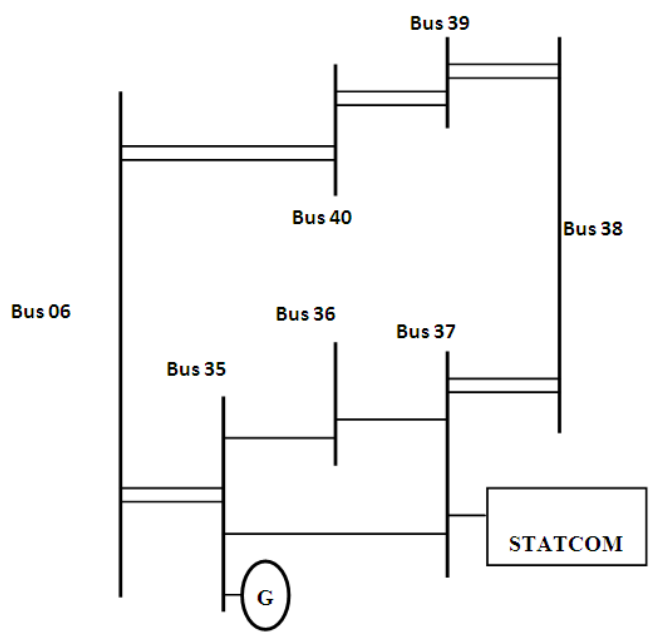

Figure (1) the largest part of northern Iraqi Grid (Mosul ring system)

\section{ESTATCOM Control Algorithm}

The schematic of STATCOM with a battery (ESTATCOM) is shown in Figure (2). The ESTATCOM is connected to the power system via a transformer. $v_{a}, v_{b}, v_{c}$ represent the three phase line to neutral system voltages at the connection point. $e_{a}, e_{b}$, and $e_{c}$ represent the fundamental components of the three phase line to neutral output voltage of the ESTATCOM 's inverter. L and R represent the resistance and reactance of the transformer. The battery is represented by an ideal DC voltage source Vs and a resistor $R_{s}$. $R_{s}$ can also accounts for any losses in inverter. $i_{a}, i_{b}, i_{c}$ represent line currents [4]. A simple model to represent the battery is used because the STATCOM is used in a transmission system for improving system's transient stability. In the short of the system transient, there should be no significant variation to the potential of the battery. The main objective of the controller is to meet the desired performance of the system requirement.

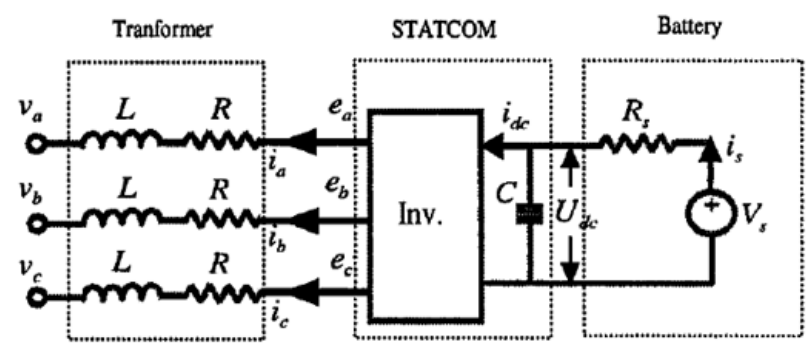

Figure (2) Equivalent Circuit of ESTATCOM

If, we assume the ESTATCOM is working in a balance condition, then, we can define a reference frame transformation and make the attained dynamic model of the STATCOM and battery simple. The reference frame coordinate is defined where the d-axis is always coincident with the instantaneous system voltage vector and the q-axis is in quadrature with it. The transformation of variables is defined in equation (1).

$$
\begin{gathered}
{[c]=\frac{2}{3}\left[\begin{array}{ccc}
\cos \theta & \cos \left(\theta-\frac{2 \pi}{3}\right) & \cos \left(\theta+\frac{2 \pi}{3}\right) \\
-\sin \theta & -\sin \left(\theta-\frac{2 \pi}{3}\right) & -\sin \left(\theta+\frac{2 \pi}{3}\right) \\
\frac{1}{\sqrt{2}} & \frac{1}{\sqrt{2}} & \frac{1}{\sqrt{2}}
\end{array}\right]} \\
{[c]^{-1}=\frac{3}{2}[c]^{T},\left[\begin{array}{l}
i_{d} \\
i_{q} \\
0
\end{array}\right]=[c]\left[\begin{array}{l}
i_{a} \\
i_{b} \\
i_{c}
\end{array}\right],\left[\begin{array}{l}
e_{d} \\
e_{q} \\
0
\end{array}\right]=[c]\left[\begin{array}{c}
e_{a} \\
e_{b} \\
e_{c}
\end{array}\right],\left[\begin{array}{l}
v \\
0 \\
0
\end{array}\right]=\left[\begin{array}{c}
v_{a} \\
v_{b} \\
v_{c}
\end{array}\right]}
\end{gathered}
$$

Where $\square$ is the angle between instantaneous system voltage vector and the a-phase axis of the abc coordinate.

In the reference frame coordinate, the equations of the AC side circuit in Figure (2) can be written as:

$$
p\left[\begin{array}{l}
i_{d} \\
i_{q}
\end{array}\right]=\left[\begin{array}{cc}
-\frac{R}{L} & \omega_{o} \\
\omega_{o} & -\frac{R}{L}
\end{array}\right]\left[\begin{array}{l}
i_{d} \\
i_{q}
\end{array}\right]+\left[\begin{array}{c}
\frac{\left(e_{d}-|v|\right)}{L} \\
\frac{e_{q}}{L}
\end{array}\right]
$$

Where:

$$
p=d / d t, \omega_{o}=2 \pi f_{o}, f_{o}=50 \mathrm{~Hz}
$$

The DC side circuit equation can be written as:

$$
\begin{gathered}
p V_{d c}=\frac{1}{C}\left(i_{s}-i_{d c}\right) \\
=\frac{1}{R \cdot C}\left(V_{s}-U_{d c}\right)-\frac{1}{C} i_{d c}
\end{gathered}
$$

The instantaneous active power on the ac side of the inverter is calculated by:

$$
P_{a c}=e_{a} i_{a}+e_{b} i_{b}+e_{c} i_{c}
$$

The relationship between the direct abc-axis and the transformed dq-axis is shown in figure (3). From this figure and after transform the abc frame to dq frame we obtained:

$$
P_{a c}=\frac{3}{2}\left(e_{d} i_{d}+e_{q} i_{q}\right)
$$

And the active power on the dc side of the inverter can express by:

$$
P_{d c}=U_{d c} i_{d c}
$$

Considering that the instantaneous active power exchanged between the ac and the dc side of the inverter should be the same, equation (6) must hold:

$$
P_{a c}=P_{d c}, U_{d c} i_{d c}=\frac{3}{2}\left(e_{d} i_{d}+e_{q} i_{q}\right)
$$

So, 


$$
i_{d c}=\frac{3}{2}\left(\frac{e_{d} i_{d}+e_{q} i_{q}}{U_{d c}}\right)
$$

When an inverter of ESTATCOM operates in SPWM mode, its output voltage must satisfy the following equations:

$$
\begin{aligned}
& e_{d}=\frac{1}{2} U_{d c} M \cos \alpha \\
& e_{q}=\frac{1}{2} U_{d c} M \sin \alpha
\end{aligned}
$$

Where $\mathrm{M}$ is the modulation index and $\alpha$ is the firing angle of the sinusoidal reference wave referring to the system voltage vector.

Combining equation (3) with equation (2) and substituting equation (8) and equation (7) into them, we can set up a dynamic model for a ESTATCOM:

$$
p\left[\begin{array}{c}
i_{d} \\
i_{q} \\
U_{d c}
\end{array}\right]=[A]\left[\begin{array}{c}
i_{d} \\
i_{q} \\
U_{d c}
\end{array}\right]+\left[\begin{array}{c}
\frac{U_{d c}}{2 L} M \cos \alpha \\
\frac{U_{d c}}{2 L} M \sin \alpha \\
-\frac{3 i_{d}}{4 C} M \cos \alpha-\frac{3 i_{q}}{4 C} M \sin \alpha
\end{array}\right]+\left[\begin{array}{c}
-\frac{h}{L} \\
0 \\
\frac{V}{V_{s} C}
\end{array}\right]
$$

Where

$$
[A]=\left[\begin{array}{ccc}
-\frac{R}{L} & \omega_{o} & 0 \\
-\omega_{o} & -\frac{R}{L} & 0 \\
0 & 0 & -\frac{1}{R_{s} C}
\end{array}\right]
$$

After linearization in the neighborhood of equilibrium point, the control system in equation (9) can be transformed to a linear system as shown in equation (10):

$$
\begin{gathered}
p\left[\begin{array}{c}
\Delta i_{d} \\
\Delta i_{q} \\
\Delta U_{d c}
\end{array}\right]=\left[A_{o}\right]\left[\begin{array}{c}
\Delta i_{d} \\
\Delta i_{q} \\
\Delta U_{d c}
\end{array}\right]+\left[B_{o}\right]\left[\begin{array}{c}
\Delta M \\
\Delta \alpha
\end{array}\right] \\
{\left[\begin{array}{c}
\Delta i_{d} \\
\Delta i_{q} \\
\Delta U_{d c}
\end{array}\right]=\left[\begin{array}{c}
i_{d}-i_{d o} \\
i_{q}-i_{q o} \\
U_{d c}-U_{d c o}
\end{array}\right],\left[\begin{array}{c}
\Delta M \\
\Delta \alpha
\end{array}\right]=\left[\begin{array}{c}
M-M_{o} \\
\alpha-\alpha_{o}
\end{array}\right]}
\end{gathered}
$$

Where

$$
\left[A_{o}\right]=\left[\begin{array}{ccc}
-\frac{R}{L} & \omega_{o} & \frac{M_{o} \cos \alpha_{o}}{2 L} \\
-\omega_{o} & -\frac{R}{L} & \frac{M_{o} \sin \alpha_{o}}{2 L} \\
-\frac{3 M_{o} \cos \alpha_{o}}{4 C} & -\frac{3 M_{o} \sin \alpha_{o}}{4 C} & -\frac{1}{R_{s} C}
\end{array}\right]
$$

$$
\left[B_{o}\right]=\left[\begin{array}{cc}
\frac{U_{d c o} \cos \alpha_{o}}{2 L} & -\frac{U_{d c o} M_{o} \sin \alpha_{o}}{2 L} \\
\frac{U_{d c o} \sin \alpha_{o}}{2 L} & \frac{U_{d c o} M_{o} \cos \alpha_{o}}{2 L} \\
-\frac{3\left(i_{d o} \cos \alpha_{o}+i_{q o} \sin \alpha_{o}\right)}{4 C} & \frac{3 M_{o}\left(i_{d o} \sin \alpha_{o}-i_{q o} \cos \alpha_{o}\right)}{4 C}
\end{array}\right]
$$

Where $\left[\Delta i_{d} \Delta i_{q} \Delta U_{d c}\right]^{\mathrm{T}}$ is the state variable vector, and $[\Delta \mathrm{M} \Delta \alpha] \mathrm{T}$ are the control variables. All the symbols with a subscription 0 in equation (10) represent the values at the equilibrium point.

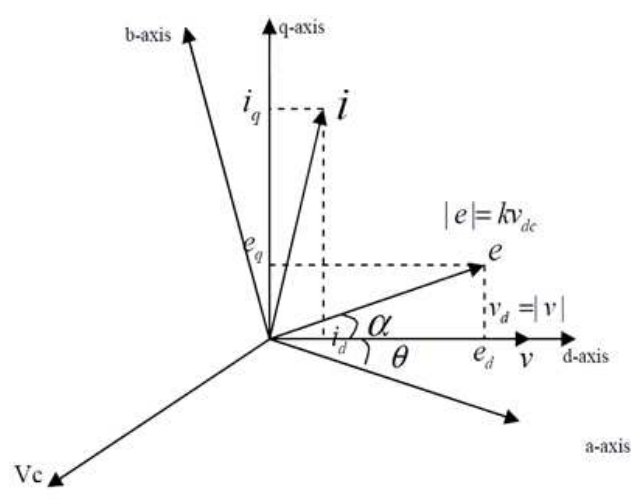

Figure (3) Relationship between the abc-axis and the dq-axis

The block diagram of ESTATCOM controller is shown in figure (4), while Figure (5) shows the block diagram of decoupled controller [5]. the decoupled proportional-integral(PI) type of controller is considered $\mathrm{K}_{\mathrm{P} 1}$ and $\mathrm{K}_{\mathrm{I} 1}$ are the gains of the reactive power regulator, where $\mathrm{K}_{\mathrm{P} 2}$ and $\mathrm{K}_{\mathrm{I} 2}$ are the gains of the Active power regulator and $\mathrm{K}_{\mathrm{P} 3}, \mathrm{~K}_{\mathrm{I} 3}$ are the gains of the $\mathrm{AC}$ current decoupled regulator. The strategy of ESTATCOM controller is to keep the active power constant while controlling the angle ( $\alpha$ ) by which the VSC voltage leads ( or lags) the line voltage vector to compensate the active power during the disturbance interval [6].

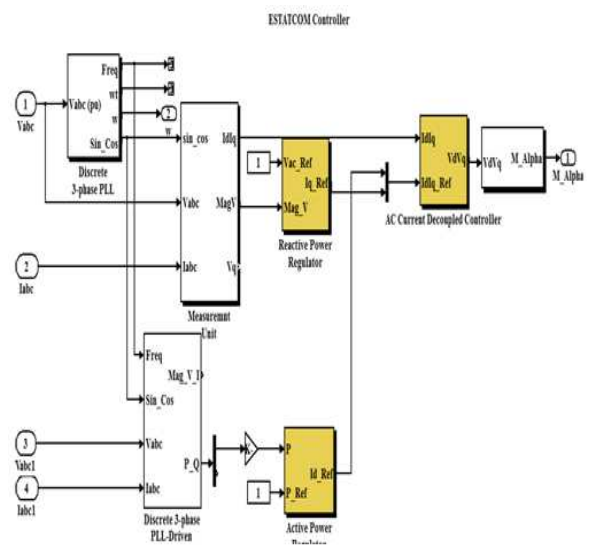

Figure (4) Simulink Model of the ESTATCOM 


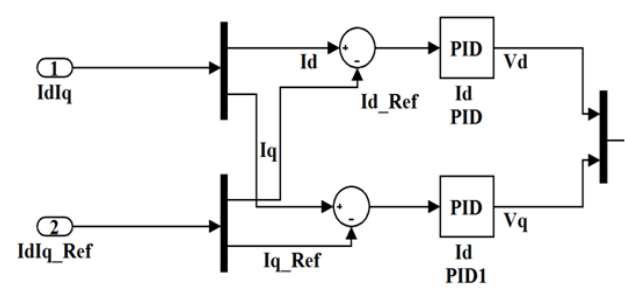

Figure (5) AC Current Decoupled Controller

\section{Simulation Results}

The effectiveness of ESTATCOM controller has been verified on bus 37 in the system discussed in section II (Mosul grid). A model of the system with ESTATCOM with the controllers has been developed in MATLAB / SIMULINK. Sudden changes in Load (figure 6) were studied here to show the controller response of ESTATCOM.

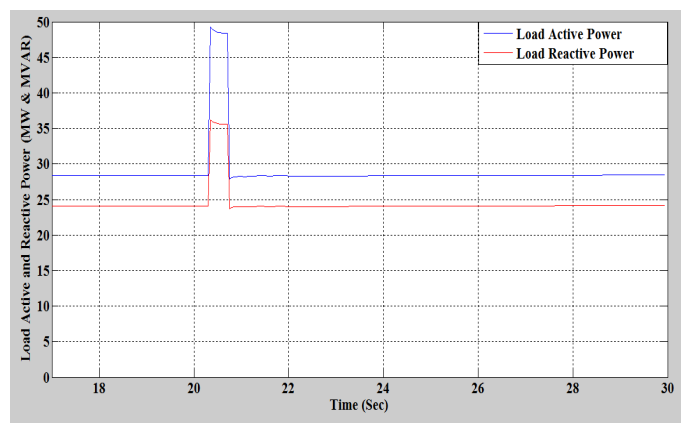

Figure (6) Load Active and Reactive Power

Figure (7) shows the active power drowns from the source1 (Mosul Dam Synchronous Generator) at load disturbance (load increased) during the interval 20.3 to 20.7 sec. This type of disturbance occurs with and without ESTATCOM. From this figure we observed that when ESTATCOM not installed the active power drawn from the source increased during that interval and there is an oscillation in active power after the load returned to its normal condition. Where installing the ESTATCOM cause the active power drown from source approximately not changing during the interval of disturbance and there is no oscillation after the load returned to its normal condition.

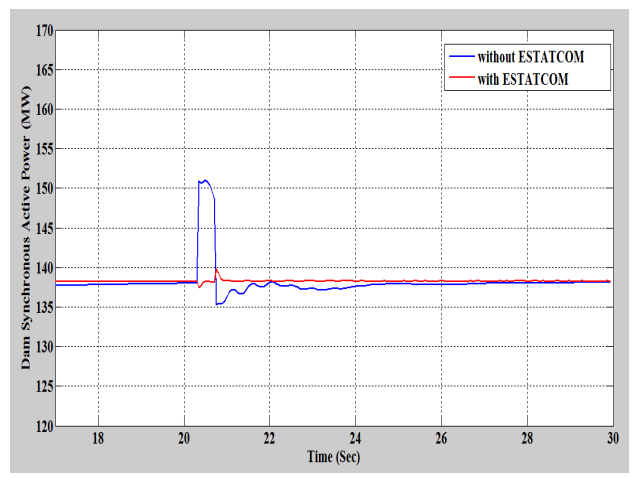

Figure (7) Mosul Dam Station Active Power
Figure (7) shows the active power drowns from the source1 (Mosul Dam Synchronous Generator) at load disturbance (load increased) during the interval 20.3 to 20.7 sec. This type of disturbance occurs with and without ESTATCOM. From this figure we observed that when ESTATCOM not installed the active power drawn from the source increased during that interval and there is an oscillation in active power after the load returned to its normal condition. Where installing the ESTATCOM cause the active power drown from source approximately not changing during the interval of disturbance and there is no oscillation after the load returned to its normal condition.

Where figure (8) shows the active power drown from the source2 (Mosul Gas Synchronous Generator) at load disturbance (load increased) during the interval 20.3 to 20.7 sec. This type of disturbance occurs with and without ESTATCOM.

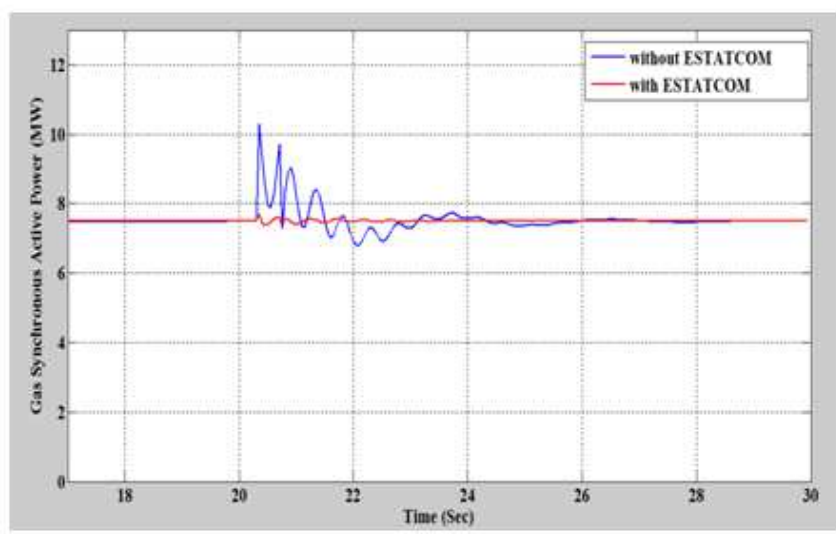

Figure (8) Mosul Gas Station Active Power

From this figure, we observed that when ESTATCOM not installed the active power drawn from the source increased during that interval and there is an oscillation in active power after the load returned to its normal condition. Where installing the ESTATCOM cause the active power drown from source approximately not changing during the interval of disturbance and there is no oscillation after the load returned to its normal condition.

Figure (9) shows the reactive power drowns from the source1 (Mosul Dam Synchronous Generator) at load disturbance (load increased) during the interval 20.3 to 20.7 sec. This type of disturbance occurs with and without ESTATCOM. From this figure we observed that when ESTATCOM not installed the reactive power drawn from the source increased during that interval, where installing the ESTATCOM cause the reactive power drown from source approximately not changing during the interval of disturbance. 


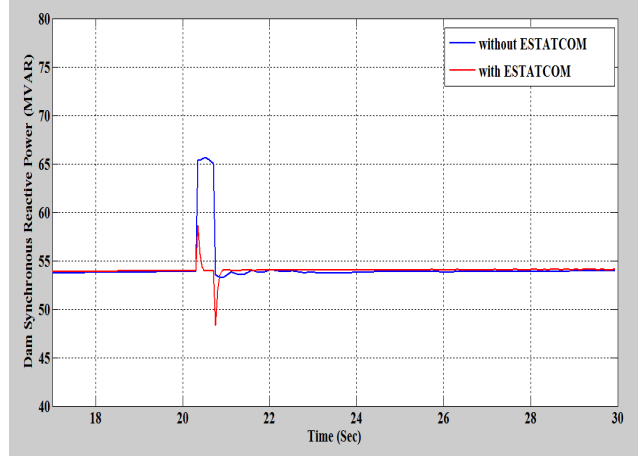

Figure (9) Mosul Dam Station Reactive Power

Where figure (10) shows the reactive power drown from the source2 (Mosul Gas Synchronous Generator) at load disturbance (load increased) during the interval 20.3 to 20.7 sec. This type of disturbance occurs with and without ESTATCOM. From this figure, we observed that when ESTATCOM not installed the reactive power drawn from the source increased during that interval. Where installing the ESTATCOM cause the reactive power drown from source approximately not changing during the interval of disturbance.

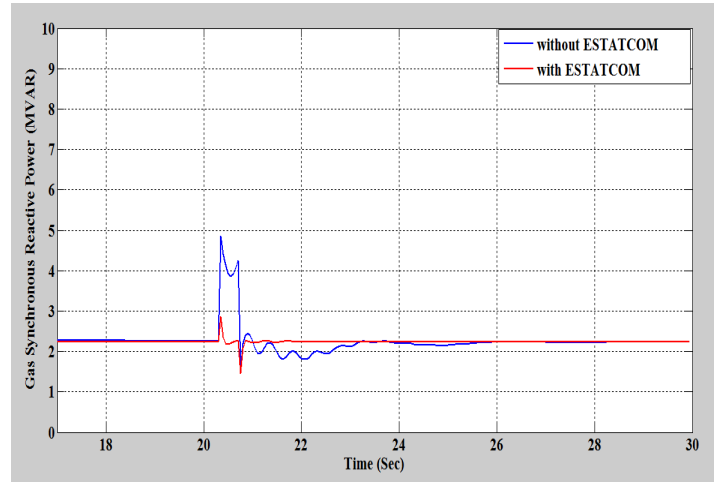

Figure (10) Mosul Gas Station Reactive Power

Figure (11) shows the ESTATCOM active and reactive power when the load increased between the interval 20.3 to 20.7 sec. From this figure, we observed that the ESTATCOM compensate the active and reactive power drown from the load during the interval of disturbance.

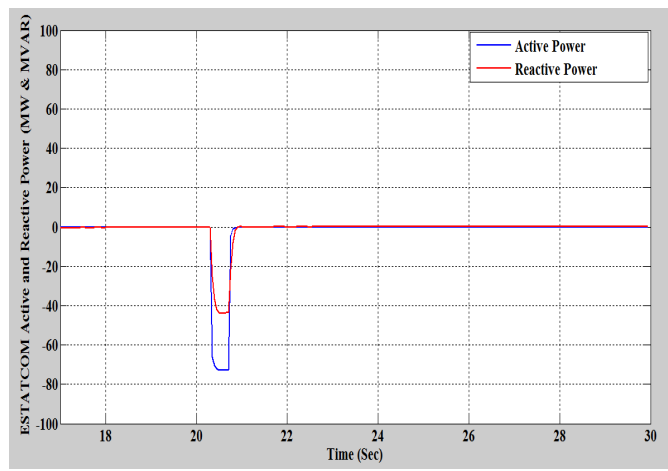

Figure (11) ESTATCOM Active and Reactive Power.
Where figure (12) and figure (13) shows the firing angle and the modulation index of the inverter used in ESTATCOM at the same condition above.

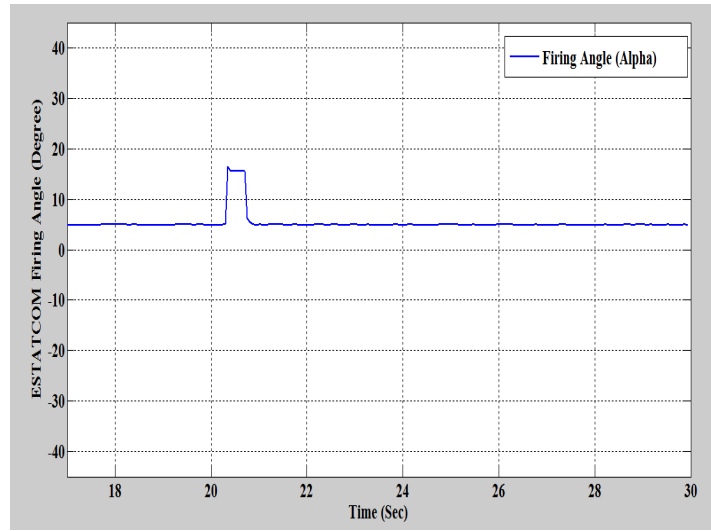

Figure (12) ESTATCOM firing angle

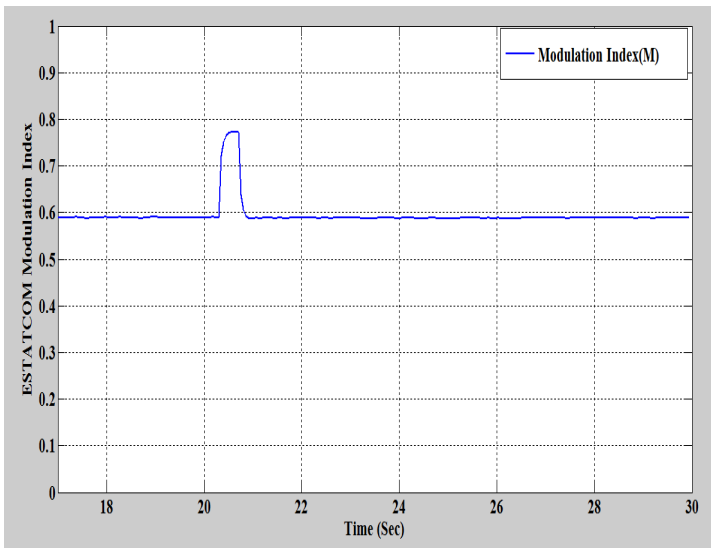

Figure (13) ESTATCOM Modulation Index

Figure (14) shows the current of energy storage element at load disturbance.

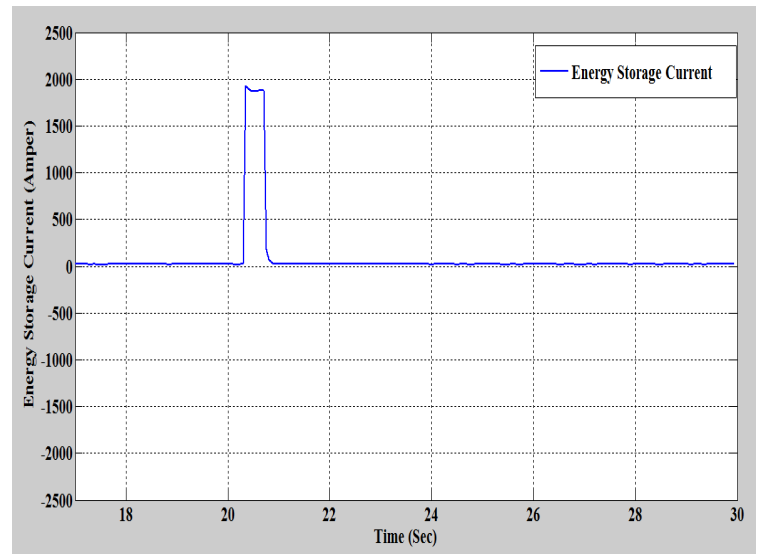

Figure (14) Energy storage current

From the figure above we observed that the ESTATCOM inject current to the system to compensate the active power and keep it constant during the interval of disturbance and prevent the oscillation occurs after the disturbance clearing. 


\section{Conclusions}

A three phase two level PWM ESTATCOM with its controller has been inserted in the Mosul ring system and some disturbances have been studied via modeling and simulation. A conventional PI controller strategy which is simple and easy to implement has been adopted.

The simulation results have shown that the ESTATCOM with the proposed controller can decrease the active power oscillation of the power system during and after the load disturbances and keep the reactive power constant during the disturbance interval. ESTATCOM model has been developed with all the necessary components and controllers in order to demonstrate its effectiveness in maintaining a fast active and reactive power regulation at any bus bar. The simulation results were compared with that of the system without compensation. Simulation results have proved the ability of the ESTATCOM to respond to the system active and reactive power requirements with satisfactory performance. The Addition of the ESTATCOM at bus 37 caused the THD of the voltage at that bus to be $1.47 \%$ which is within IEEE-519 standards [7].

The performance of ESTATCOM with its controller was very close (within $\pm 98 \%$ ) of the nominal value of voltage. The response time took about two cycles.

\section{Appendix (1)}

\section{Parameters (Base- 100MVA)}

IGBT-VSCs based two-level 12-Pulse, \pm 100MVAR ESTATCOM.

\section{A. Converter Parameters}

IGBT-VSC Converters; No. of pulses-12; Nominal AC voltage-132kV; DC link voltage- $12 \mathrm{kV}$.

\section{B. Transformer Units}

Each 3-winding Transformer Rating: (100/3) MVA, $50 \mathrm{~Hz}, 132 \mathrm{kV} / 12 \mathrm{kV}, 12 \%(\mathrm{X})$.

\section{PI-controller Gain}

Reactive Power Regulator: $\mathrm{K}_{\mathrm{p}}=0, \mathrm{~K}_{\mathrm{I}}=100$; AC Current Decoupled Regulator: D-axis controller: $\mathrm{K}_{\mathrm{pd}}=3, \mathrm{~K}_{\mathrm{Id}}=1$; Q-axis controller: $\mathrm{K}_{\mathrm{pq}}=3, \mathrm{~K}_{\mathrm{Iq}}=1$; Active Power Regulator: $\mathrm{K}_{\mathrm{p}}=1, \mathrm{~K}_{\mathrm{i}}=70$.

\section{Thevenin's Equivalent Voltage Source}

Nominal Voltage: $132 \mathrm{kV}$; Source impedance:1\% System frequency: 50Hz; Short circuit level: 1000MVA; X/R ratio-7.

\section{Appendix (2)}

The model of Mosul ring with ESTATCOM using MATLAB SIMULINK

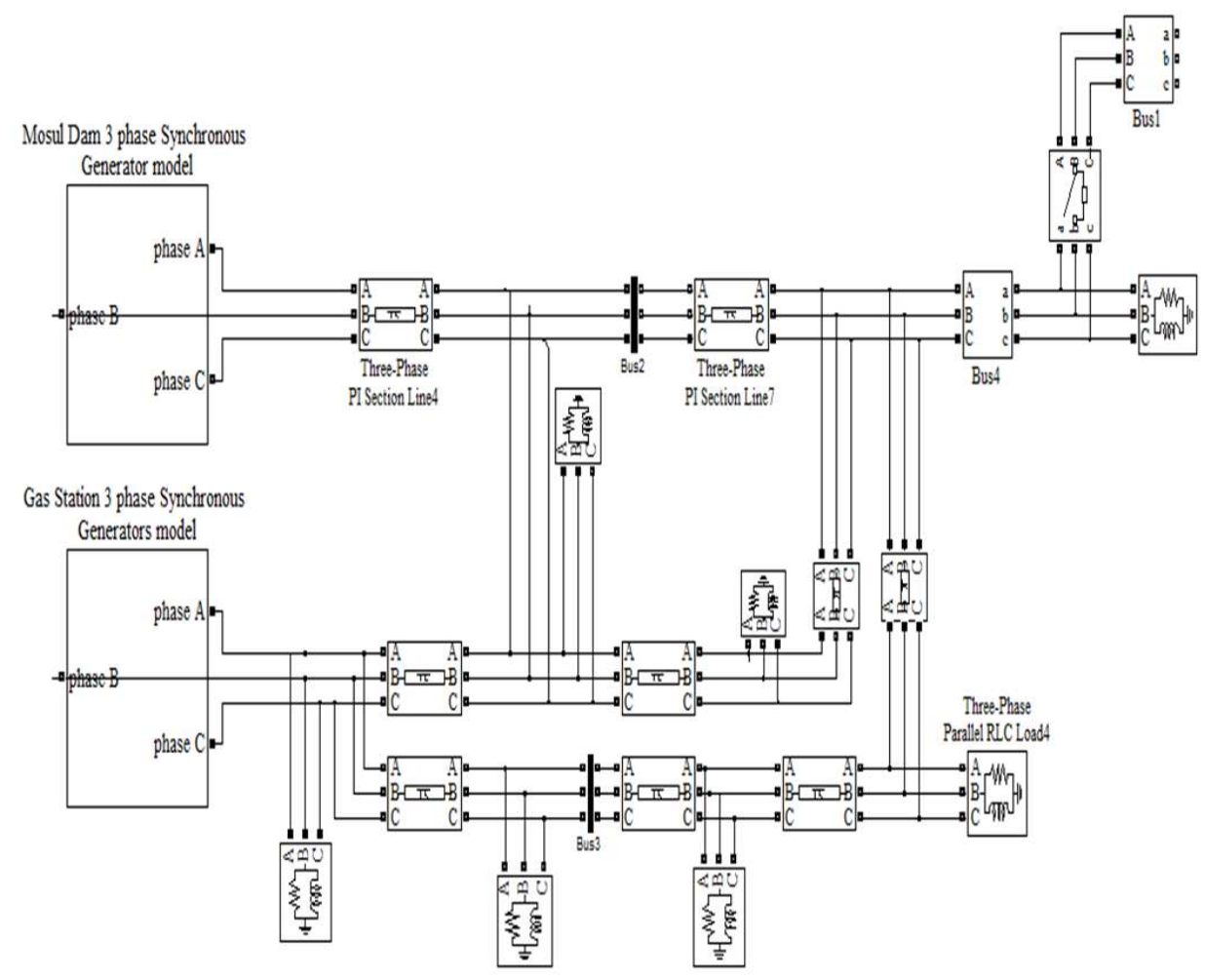

(a) 


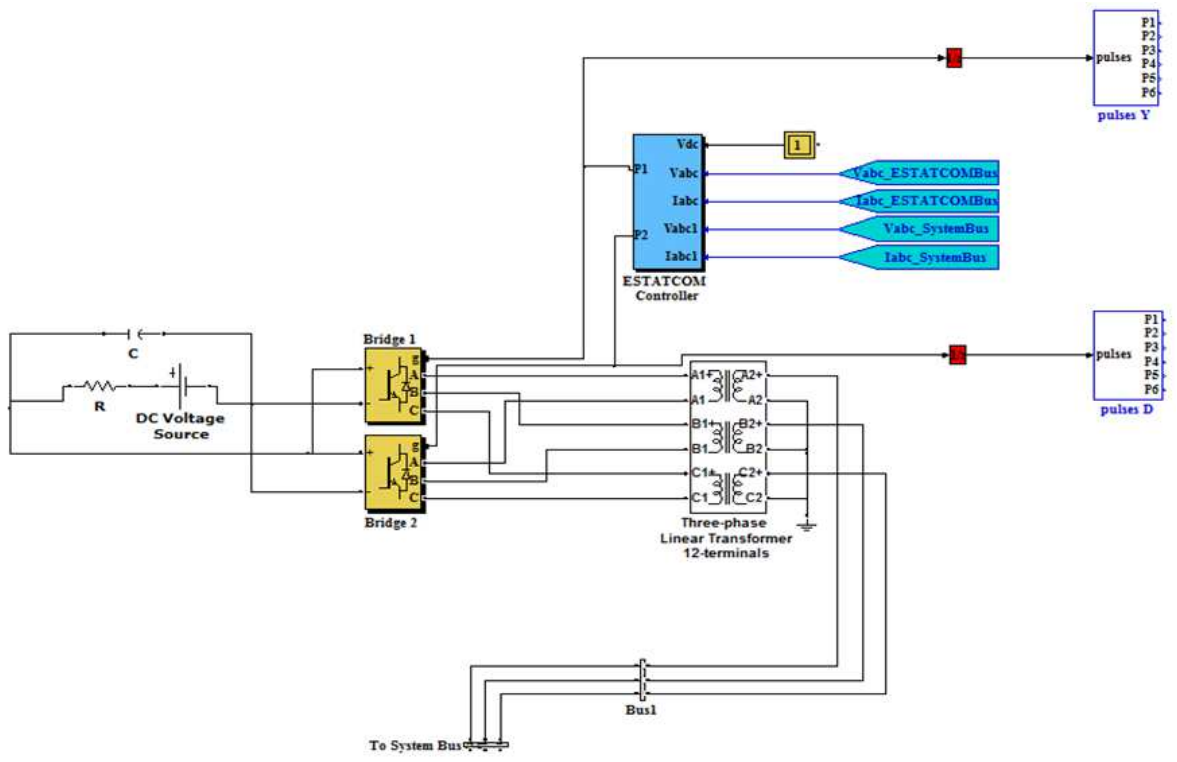

(b)

(a) The model of Mosul ring using MATLAB/SIMULINK

(b) ESTATCOM model using MATLAB/SIMULINK

[4] R. Kuiava, R. A. Ramos and N. G. Bretas, "Control Design of a STATCOM with Energy Storage System for Stability and Power Quality Improvements," IEEE International Conference on Industrial Object Identifier, 2009.

[1] Dr. Dhiya A. Al-Nimma, Dr. Majed S. M. Al-Hafid and Saad Enad Mohamed "Voltage Profile Improvements of Mosul City Ring System by STATCOM Reactive Power Control", Acemp - Electromotion 2011, 8 - 10 September 2011 Istanbul - Turkey.

[2] Dhiya A. Al-Nimma, Majed S. M. Al-Hafid and Saad Enad Mohamed "Simultaneous Active and Reactive Power Control of ESTATCOM for Improving Mosul City Ring System" The First National Conference for Engineering cience, Baghdad-Iraq, 7-8 Nov. 2012.

[3] Majed S. M. Al-Hafid "Simulation of a Static Synchronous Compensator in the $132 \mathrm{KV}$ Mosul Ring System" a PHD Thesis , University of Mosul - Iraq, 2006.

[5] Vasudeo B. Virulkar and Mohan V. Aware, "Modeling and Control of DSTATCOM with BESS for Mitigation of Flicker, "Asian Power Electronics Journal, Vol. 4 No.1 April 2010.

[6] B. Singh and R. Saha, "A New 24-Pulse STATCOM for Voltage Regulation," International Conference on Power Electron. Drives and Energy Systems, 2006. PEDES '06, 12-15 Dec. 06, pp. 1-5.

[7] Alper Cetin and Muammer Ermi, s, Member, IEEE, "VSC-Based D-STATCOM With Selective Harmonic Elimination," IEEE TRANSACTIONS ON INDUSTRY APPLICATIONS, VOL. 45, NO. 3, MAY/JUNE 2009. 